\title{
Traumas faciais: uma revisão sistemática da literatura
}

\author{
Facial trauma: a systematic review of literature
}

Milena Tatiana Ferreira Lima de Moura*

Rafael Moreira Daltro*

Tatiana Frederico de Almeida**

\section{Resumo}

Introdução: os traumatismos craniofaciais são observados, diariamente, em hospitais de urgência e acometem especialmente jovens, tendo como causas importantes a agressão física e os acidentes de trânsito. A epidemiologia do trauma de face é importante para seu correto conhecimento e tratamento. Dessa forma, faz-se necessário estabelecer a ocorrência e etiologia desse agravo, de modo a melhor compreendê-lo. Objetivo: o objetivo deste estudo foi realizar uma revisão sistemática da literatura, analisando estudos nacionais sobre traumas faciais quanto aos objetivos, metodologia e resultados nos últimos cinco anos. Materiais e método: revisão sistemática da literatura, na qual dezesseis estudos epidemiológicos foram rastreados nas bases de dados Lilacs, Scielo e BBO do período entre 2010 e 2015. Resultados: o sexo mais acometido foi o masculino. A mandíbula foi o local em que ocorreu maior número de traumas. $A$ faixa etária entre 19 e 40 anos foi a mais afetada. A principal etiologia dos traumas faciais foi a violência interpessoal. Conclusões: políticas de saúde pública devem ser traçadas no intuito de controlar e prevenir esse problema, sendo que a ocorrência dos traumatismos pode ser reduzida por medidas educativas.

Palavras-chave: Traumatismos faciais. Lesões faciais. Epidemiologia.

\section{Introdução}

Segundo Freire ${ }^{1}$ (2001), o trauma pode ser considerado o conjunto das perturbações causadas subitamente por um agente físico de etiologia, natureza e extensão muito variadas, podendo estar situado nos diferentes segmentos corpóreos. Eles estão entre as principais causas de morte e morbidade no mundo, segundo dados da Organização Mundial de Saúde. As lesões da cabeça e da face podem representar $50 \%$ de todas as mortes traumáticas ${ }^{2}$.

Sendo a face a verdadeira região de expressão da alma, em que todos os sentimentos são representados, o conhecimento das particularidades dos traumatismos faciais é importante, pois compromete definitivamente a vida do ser humano e, quando mal abordados, deixam sequelas, marginalizando o indivíduo do convívio social, gerando incapacidade de trabalho, condenando-o ao segregamento econômico $^{3}$.

A etiologia do trauma facial é multifatorial. A predominância maior ou menor de cada caso está relacionada a vários fatores, como: violência, idade, sexo, classe social, local de moradia (urbana ou rural) da população estudada.

\footnotetext{
Graduada em Odontologia pela Escola Bahiana de Medicina e Saúde Pública, Salvador, Bahia, Brasil

Graduando do curso de Odontologia da Escola Bahiana de Medicina e Saúde Pública, Salvador, Bahia, Brasil/Bolsista do Programa de Educação Tutorial PETODONTO-BAHIANA

* Doutora em Saúde Coletiva pela Universidade Federal da Bahia, professora Adjunta do Curso de Odontologia da Escola Bahiana de Medicina e Saúde Pública, Salvador, Bahia, Brasil
} 
No que tange à violência, não há um fator único que explique por que alguns indivíduos se comportam violentamente com outros ou por que a violência é mais comum em algumas comunidades do que em outras. Ela é o resultado da complexa interação dos fatores individuais, relacionais, sociais, culturais e ambientais. Compreender como esses fatores estão relacionados com a violência é um dos passos importantes na abordagem da saúde pública para a prevenção da violência. A violência custa às nações valores humanos e econômicos, extraindo das economias mundiais a cada ano muitos bilhões de dólares em tratamentos de saúde, gastos legais, ausência do trabalho e produtividade perdida ${ }^{4}$.

Existe uma tendência mundial de maior prevalência dos traumas faciais em homens jovens. Estudo realizado por Silva et al. ${ }^{5}$ (2011), revelou que as lesões faciais acometeram em sua grande maioria pacientes homens, em uma proporção de aproximadamente 4:1. Os pacientes na fase adulto jovem (18 a 40 anos) constituíram a faixa mais prevalente em ambos os sexos, mas com predomínio estatisticamente significante dos homens em todos os mecanismos causadores dos traumatismos faciais. Porém, principalmente nas três últimas décadas, há um aumento crescente dos traumas em mulheres, geralmente, na faixa etária até 40 anos. Isso se deve às mudanças comportamentais da mulher na sociedade ${ }^{6}$.

Na faixa etária escolar, as crianças experimentam maior independência e interação com a sociedade, tendendo a se expor mais aos traumas, aumentando, assim, a incidência das fraturas. A queda e os acidentes automobilísticos são os principais fatores etiológicos de traumas faciais nessa idade ${ }^{7}$.

Para Souza et al..$^{7}$ (2010), assim como entre os adultos, na infância o trauma também está mais associado ao sexo masculino. Tal fato pode ser devido a diferenças de comportamentos ligadas a características peculiares a cada sexo. Os traumas domésticos por agressão às crianças não são raros. Normalmente, são pacientes mais jovens e com múltiplas fraturas em diferentes estágios de consolidação, caracterizando a Síndrome da Criança Espancada, que é de notificação compulsória pelo profissional da saúde. De um modo geral, a incidência de fratura maxilofacial é menor em crianças do que em adultos.

Nos idosos, a queda é o principal mecanismo de trauma e geralmente resulta de múltiplas causas patológicas. Mecanismos fisiológicos como propriocepção alterada, fraqueza, tremor e reflexos diminuídos facilitam a queda. Esta é a faixa etária menos acometida pelo trauma geral e de face, mas sua recuperação é mais demorada, e eventuais complicações são frequentes ${ }^{8}$.

Para Wulkan et al. ${ }^{8}$ (2005), uma agressão localizada na face não envolve apenas tecidos moles e ossos, podendo estender-se para outras áreas próximas.
O diagnóstico e tratamento das lesões faciais envolvem um atendimento de abrangência multidisciplinar, envolvendo principalmente as especialidades de trauma, oftalmologia, cirurgia plástica, maxilofacial e neurocirurgia. A mandíbula e o nariz são os principais locais das fraturas, seguidos pelo zigoma $^{7,9}$.

Em vista da alta incidência e prevalência dos traumatismos faciais, é preciso ter uma clara compreensão dos padrões das lesões que acometem a face para que possam auxiliar na assistência emergencial, a fim de propiciar condutas e tratamentos adequados e efetivos. Além disso, tais informações epidemiológicas podem também ser utilizadas para implantação de protocolos direcionados à realização de programas de prevençãa ${ }^{10}$.

O objetivo principal dessa revisão sistemática da literatura foi realizar uma análise dos estudos de natureza epidemiológica nacionais sobre traumas faciais quanto aos seus objetivos, metodologia e resultados de 2010 a 2015.

\section{Materiais e método}

Para realização desta revisão sistemática de literatura foram selecionados estudos epidemiológicos observacionais realizados entre 2010 e 2015 no Brasil, em que o traumatismo de face foi o evento de interesse. As bases de dados empregadas para o rastreamento foram LILACS, BBO e SCIELO utilizando-se a combinação das palavras-chave: traumatismos faciais, lesões faciais, epidemiologia (facial trauma, facial injuries, epidemiology). Essa pesquisa bibliográfica foi finalizada em junho de 2015.

Estudos epidemiológicos publicados em português foram incluídos nessa revisão. Foram considerados relevantes aqueles que apresentavam levantamento de dados epidemiológicos e informações sobre os traumas craniofaciais.

Durante um primeiro rastreamento, foi incluída apenas a combinação das palavras-chave. Foram excluídas as referências de artigos sem resumo disponível e aqueles não relacionados ao tema de interesse específico.

Posteriormente, em um segundo rastreamento, foram selecionados resumos das publicações de natureza epidemiológica que investigaram o trauma de face. Os estudos foram analisados quanto a ano de publicação, local de realização, população do estudo, objetivos, metodologia e resultados.

\section{Resultados}

Utilizando as palavras traumatismos faciais, lesões faciais e epidemiologia, foram encontrados um total de 113 artigos nas bases de dados Lilacs, Scielo e BBO. Considerando os critérios de inclusão, 16 foram selecionados na base Lilacs, 2 na Scielo e 
2 na $\mathrm{BBO}$, sendo que os últimos também constavam na base de dados Lilacs.

Todos os estudos utilizaram o desenho do tipo corte transversal (Quadro 1) $)^{5,7,9-22}$.

Os estudos empíricos foram analisados em função dos seguintes aspectos: sexo, faixa etária, local e causas do trauma facial.

Com relação ao sexo, apenas um artigo relatou associação negativa para o sexo masculino como sendo o principal acometido em acidentes com fraturas faciais ${ }^{21}$. Os demais artigos associaram, positivamente, o sexo masculino com os traumas faciais $^{5,7,9-22}$.

Em oito estudos a mandíbula foi o local da face mais acometido $0^{5,7,9-11,18,20,22}$, seguido dos ossos nasais em quatro estudos ${ }^{12,14,15,19}$.

Alguns estudos selecionados apontam como principal fator etiológico para os traumas faciais a agressão física. Nessas investigações a agressão física foi associada com o local de residência dos indivíduos, sendo uma associação positiva com o fato de residir na capital do estado ${ }^{10-12,15,21}$. Para outros autores, o principal agente etiológico foram os acidentes de trânsito, sendo os mais prevalentes aqueles envolvendo motocicletas e carros de passeio ${ }^{5,7,9,18,22}$.

Para todos os autores dos artigos selecionados, a faixa etária mais acometida foi entre 19 e 40 anos, com média de 30 anos para o sexo masculino e 40 anos para o sexo feminino ${ }^{5,7,9-22}$.

$\mathrm{O}$ verão foi a época do ano de maior acometimento dos traumas faciais ${ }^{7}$. Em um estudo a maioria das vítimas de traumas faciais era de cor bran$\mathrm{ca}^{5}$, mas houve estudo que a etnia parda foi predominante ${ }^{21}$. Observou-se que $62,6 \%$ das vítimas de traumatismos faciais eram do interior do estado $0^{5,18}$.

Nas mulheres, predominaram as lesões do tipo contundente e em mais de uma região corporal. $\mathrm{Na}$ face, a região mais acometida pela violência foi o terço médio. $\mathrm{O}$ agressor foi predominantemente $\mathrm{o}$ cônjuge ${ }^{19}$.

Em crianças e adolescentes as quedas $(47,26 \%)$ foram o agente etiológico mais prevalente. A faixa etária de maior acometimento foi de 1 a 4 anos (28,5\%), houve prevalência entre o sexo masculino $(65 \%)$ e a lesão coronária dentária ocorreu em $20,23 \%$ das crianças ${ }^{14,17}$.

O período noturno $(35,90 \%)$ e os domingos $(17,39 \%)$ foram os principais períodos dos acidentes nas crianças e os dentes mais acometidos foram os incisivos centrais $(45,64 \%)^{17}$.

\section{Discussão}

A epidemiologia do trauma facial foi estudada e analisada nesta revisão a partir da elaboração de um quadro resumo composto por 16 estudos diretamente relacionados ao tema, os quais foram publicados nos anos de 2010 a 2015 e que se encontravam disponíveis nas bases de dados BBO, LILACS e SCIELO. Os aspectos analisados por meio desse quadro resumo foram: objetivos, metodologia e os resultados encontrados em cada estudo.

Muitos fatores se associam aos traumas faciais, principalmente os sociodemográficos. Nossos achados revelaram que $94 \%$ dos estudos utilizados para essa revisão sistemática apresentaram uma relação positiva entre o trauma facial e o sexo masculi$\mathrm{no}^{5,7,9-20,22,23}$. Apenas um estudo encontrou associação positiva entre o sexo feminino e o trauma facial ${ }^{21}$. Esse resultado seria indicação de uma tendência para o aumento da incidência nas mulheres, cada vez mais expostas aos fatores de risco desse tipo de trauma, como um maior número de mulheres motoristas, a associação de álcool e direção, a inserção delas em trabalhos extradomésticos e à prática de esportes como atividade de lazer e saúde, inclusive esportes que envolvem contato físico ${ }^{6,24}$.

Atualmente, a violência contra a mulher é um problema social e de saúde pública, consistindo num fenômeno mundial que não respeita fronteiras de classe social, raça/etnia, religião, idade e grau de escolaridade. Independentemente do status da mulher, o locus da violência continua sendo gerado no âmbito familiar ${ }^{25}$.

A literatura revela que ainda é dificultoso o estabelecimento da relação existente entre a violência doméstica contra a mulher e traumatismos bucomaxilofaciais. Tal dificuldade pode ser justificada pela frequente omissão da mulher sobre o verdadeiro motivo das agressões sofridas. Observa-se que as mulheres buscam o atendimento dias após o episódio, tentando esconder dos profissionais que a atendem a causa de suas lesões ${ }^{25}$.

A maior ocorrência de traumas no sexo masculino pode ser atribuída ao fato de que eles são em maior número no trânsito, principalmente nas rodovias; praticam mais esportes de contato físico; frequentam "bares" como atividade social e, consequentemente, abusam mais de drogas, entre elas o álcool, antes de dirigirem ${ }^{23}$.

Diversos fatores associam-se aos traumas faciais, principalmente quando se fala nas desigualdades em saúde e nas condições demográficas, sociais e culturais dos diferentes grupos populacionais. Estudos vêm mostrando que esse agravo é predominante em adultos jovens entre os 19 e 40 $\operatorname{anos}^{5,7,9-22}$. A partir dos artigos selecionados, pode-se observar que a média de idade de acometidos por trauma facial do sexo masculino foi de 30 anos e para o sexo feminino a média foi de 40 anos. Traumas decorrentes de acidente de carro, motocicleta, esporte e ferimento de arma de fogo tiveram sua maior frequência nessa faixa etária. Isso representa um problema socioeconômico, pois trata-se de uma população predominantemente produtiva. A prevalência nessas décadas de vida pode ser atribuída a um maior acesso dos jovens a veículos automotores, direção em alta velocidade e uma pequena divulgação e fiscalização das leis de trânsito, além 
do aumento da violência externa pelas características psicossociais de violência da sociedade urbana atual, conflitos socioeconômicos e emocionais a que os jovens estão submetidos ${ }^{8}$. Assim, é compreensível que essa violência ocorra mais entre jovens pela sua inquietação e desobediência às normas, influenciado por mudanças comportamentais e morais extremamente rápidas ${ }^{2}$.

As fraturas de mandíbula $a^{5,7,9-11,18,22}$ e nasal $^{12,14,15,19}$ foram as lesões mais prevalentes nos estudos analisados. Tal fato foi corroborado em diferentes estudos. O fato de o nariz ocupar uma posição central na face torna-o uma estrutura facilmente fraturada devido à pequena espessura dos ossos nasais ${ }^{23}$. As lesões associadas foram decorrentes, principalmente, de violência interpessoal, acidentes automobilísticos e por motocicletas, aliás, os mesmos mecanismos responsáveis pela maior frequência de fratura mandibular. A ocorrência de lesões associadas pode sofrer uma modificação com relação à região geográfica considerada, levando-se em conta os hábitos de vida das diferentes populações ${ }^{26}$. De qualquer modo, a natureza e frequência dessas lesões continuam a ser significantes, sendo fundamentais o diagnóstico e cuidados multiprofissionais, sempre que necessário ${ }^{13}$.

Quanto à etiologia do trauma, os acidentes de trânsito foram predominantes nos estudos ${ }^{5,7,9,18,22}$, tendo maior relevância os acidentes envolvendo motociclistas. A violência interpessoal também apareceu frequentemente como causa dos traumas faciais $^{10-12,15,21}$

Tem-se observado uma mudança na etiologia dos traumas faciais. A violência interpessoal passou a liderar as estatísticas nos estudos mais recentes, sendo antes os acidentes automobilísticos a principal etiologia deste tipo de trauma ${ }^{2}$. Isso se deve principalmente às políticas públicas, que visam a um controle maior do excesso de velocidade nas vias e estimulam o uso do cinto de segurança. Além disso, a proibição de dirigir alcoolizado, e a introdução de air bags e barras de proteção lateral diminuíram a incidência de fraturas faciais, como também sua complexidade ${ }^{23}$.

Embora alguns fatores de risco sejam específicos de certos tipos de violência, os vários tipos de violência, em geral, têm fatores de risco comuns. Normas socioculturais predominantes, como: pobreza, isolamento social, abuso de álcool, de drogas e acesso a armas de fogo são fatores de risco de mais de um tipo de violência ${ }^{4}$.

Foi possível observar que os estudos realizados em municípios do interior apresentaram os acidentes por motocicletas como principal causa do trauma facial. Naqueles realizados em capitais das unidades federativas, a principal causa do trauma facial foi a violência interpessoal seguido dos acidentes automobilísticos, demonstrando um limite nos estudos no que diz respeito às características locais, ambientais e sociais. Essas características serão responsáveis pelas maiores ou menores incidências de cada população estudada.

Em todos os estudos analisados, o desenho de escolha foi o de corte transversal ${ }^{5,7,9-22}$. Sabe-se que esse desenho não permite garantir a antecedência temporal da exposição em relação ao efeito, porém é mais exequível. Ademais, as amostras são de conveniência, muitas vezes pequenas, impróprias para comparações estatísticas, provenientes de serviços de saúde, públicos ou privados, instituições de ensino e serviços de segurança pública, o que pode não refletir de fato a realidade.

Recomenda-se, assim, a realização de investigações epidemiológicas mais apuradas metodologicamente, tanto do ponto de vista do desenho de estudo, como das amostras avaliadas e das análises estatísticas. Por outro viés, também é conveniente que análises qualitativas sejam realizadas, com o intuito de pesquisar em profundidade aspectos culturais e psicossociais geradores de traumas faciais que se tornam invisíveis em pesquisas de cunho quantitativo, mas cuja compreensão muito contribuiria para o controle desse agravo na sociedade, pelo caminho da educação.

Em relação aos traumatismos craniofaciais associados às mulheres, pode-se observar que há, muitas vezes, uma omissão por parte dessas no que se diz respeito à etiologia do trauma sofrido, pelo fato de que, na grande maioria dos casos, os agressores são os próprios familiares ${ }^{19}$. Esse fato acaba tornando os resultados das pesquisas incompatíveis com a realidade. Novos estudos devem ser realizados de forma a diagnosticar o tipo de traumatismo pela historia familiar e psicossocial e pelas características das vítimas de agressão.

\section{Considerações finais}

Os traumas faciais acometem, preferencialmente, homens adultos, jovens sendo mais decorrentes de violência interpessoal e acidentes automobilísticos. A faixa etária mais atingida foi de 21 a 30 anos, principalmente por essa população estar mais exposta aos fatores de risco para o trauma. Os locais mais acometidos pelo trauma na face foram a mandíbula e os ossos nasais. O consumo de bebidas alcoólicas e/ou drogas foi um fator associado a todas as categorias que ocasionaram traumatismos.

As políticas de saúde pública devem ser traçadas no intuito de controlar e prevenir a ocorrência dos traumatismos, podendo ser reduzida por medidas educativas, como o uso rotineiro de cinto de segurança e capacete; menor consumo de bebidas alcoólicas e drogas e estratégias para lidar com situações de violência.

A divulgação contínua de dados relacionados à epidemiologia dos traumas faciais é de extrema importância, devido à tendência de mudança na frequência dos mecanismos causadores, permitindo a 
elaboração de novas formas de prevenção e tratamento dessas lesões, cuja complexidade é reconhecida na literatura, envolvendo, necessariamente, atuações multidisciplinares.

\section{Abstract}

Introduction: craniofacial trauma is observed daily in urgency hospitals, especially affecting young adults. Physical aggression and traffic collisions are its major causes. The epidemiology of facial trauma is important for correct understanding and treatment. Thus, it is necessary to establish the incidence and etiology of this injury in order to achieve a better understanding on the matter. Objective: this study aimed to perform a systematic review of the literature, analyzing Brazilian studies on facial trauma as to their objectives, methodology, and results within the last five years. Materials and method: systematic literature review, in which sixteen epidemiological studies conducted between 2010 and 2015 have been tracked in the Lilacs, Scielo, and BBO databases. Results: men were mostly affected, the mandible was where the highest number of traumas occurred, the age group between 19 and 40 years was the most affected, and the main etiology of facial trauma was interpersonal violence. Conclusions: public health policies must be drawn in order to control and prevent this problem, especially considering that the incidence of traumas may be reduced by educational measures.

Keywords: Facial traumas. Facial injuries. Epidemiology.

\section{Referências}

1. Freire E. Trauma: a doença dos séculos. São Paulo: Atheneu; 2001.

2. Macedo JLSM, Camargo LM, Almeida PF, Rosa SC. Perfil epidemiológico da trauma de face dos pacientes atendidos no pronto socorro de um hospital publico. Rev Col Bras Cir 2008; 35(1):9-1.

3. Falcão MFL, Segundo AVL, Silveia MMF. Epidemiological Study of 1758 Facial Fractures Treated at Hospital da Restauração in Recife, Pernambuco, Brazil. Rev Cir Traumatol Buco-Maxilo-Fac, 2005; 5(3):65-72.

4. Dahlberg LL, Krug EG. Violência: um problema global de saúde pública. Ciên Saúde Colet 2007; 11(Sup):1163-78.

5. Silva JJL, Lima AAAS, Melo IFS, Pinheiro-Filho TRC. Trauma facial: análise de 194 casos. Rev Bras Cir Plast 2011; 26(1):37-41.

6. Chrcanovic BR, Freire-Maia B, Souza LN, Araújo VO, Abreu MH. Facial fractures: a 1-year retrospective study in a hospital in Belo Horizonte. Braz Oral Res 2004; 18(4):322-8.

7. Souza DFM, Santili C, Freitas RR, Akkari M, Figueiredo MJPSS. Epidemiologia das fraturas em crianças num pronto-socorro de uma metrópole tropical. Acta Ortop Bras 2010; 18(6):335-8.

8. Wulkan M, Pereira Jr GP, Botter MA. Epidemiologia do Trauma Facial. Rev Assoc Med Bras 2005; 51(5):290-5.

9. Martins RHG, Ribeiro CBH, Fracalossi T, Dias NH. A lei seca cumpriu sua meta em reduzir acidentes relacionados à ingestão excessiva de álcool? Rev Col Bras 2013; 40(6):438-42.
10. Carvalho TBO, Cancian LRL, Marques CG, Piatto VB, Maniglia JV, Molina FD. Six years of facial trauma care: na epidemiological analysis of 355 cases. Bras J Otorrinal 2010; 76(5):556-74.

11. Martins-Junior JC, Kein FS, Helena ETS. Aspectos epidemiológicos dos pacientes com traumas maxilofaciais no Hospital Geral de Blumenau, SC de 2004 a 2009. Arq Int Otorrinolarigol 2010; 14(2):192-8.

12. Marques AC, Guedes LJ, Sizenando RP. Incidência e etiologia das fraturas de face na região de Venda Nova - Belo Horizonte, MG - Brasil. Rev Med MinasGerais 2010; 20(4):500-2.

13. Cavalcanti AL, Assis KM, Cavalcanti JR, Xavier AF, Aguiar YPC. Traumatismos maxilofaciais em crianças e adolescentes em Campina Grande, Paraíba, Brasil. Pesq Bras Clin Integ 2012; 12(3):439-45.

14. Cavalcanti AL, Santos FG, Peixoto LR, Gonzaga AKG, Dias CHS, Xavier AFC. Ocorrência de injúrias orofaciais em praticantes de esportes de luta. Pesq Bras Odontop Clin Integr 2012; 12(2):223-8.

15. Stolz ASB, Meller FB, Quesada GA, Bergoli C, Escobar $\mathrm{CAB}$, Martins EM. Análise epidemiológica de fraturas bucomaxilofaciais em pacientes atendidos no Hospital universitário de Santa Maria - HUSM: um estudo retrospectivo. Rev Odontol BrasCentral 2011; 20(53):129-35.

16. Borguese B, Calderoni DR, Passeri LA. Estudo restrospectivo da abordagem das fraturas nasais no Hospital de clínicas da Unicamp. Rev Bras Cir Plast 2011; 26(4):608-12.

17. Silva HR, Melchioretto EF, Batista OS, Colombo MCSS. Perfil epidemiológico de trauma dentário e facial em Curitiba. Arch Oral Res 2011; 7(3):267-73.

18. Silva JJL, Lima AAAS, Dantas TB, Frota MHA, Parente RV, Lucena ALSPN. Fratura de mandíbula: estudo epidemiológico de 70 casos. Rev Bras Cir Plast 2011; 26(4):645-8.

19. Santana JLB, Silva BS, Santos JC, Andrade PO, Moreno BLG, Campllo RIC, Et al. Lesões corporais e faciais em mulheres submetidas a exame de corpo de delito em Recife/PE, Brasil. Odontol Clin Cient 2011; 10(2):133-6.

20. Santos CML, Musse JO, Cordeiro IS, Martins TMN. Estudo epidemiológico dos traumas bucomaxilofaciais em um hospital público de Feira de Santana, Bahia de 2008 a 2009. Rev Bai Sau Pub 2010; 36(2):502-13.

21. Santos MS, Almeida TF, Silva RA. Traumas faciais: Perfil epidemiológico com ênfase nas características sociais e demográficas e características da lesão, Salvador BA, 2008. Rev Bai Sau Pub 2013; 37(4):1003-14.

22. Aragão JA, Reis FP, Froes-Junior GRT, Costa MD. Perfil epidemiológico dos pacientes com fraturas dos ossos da face em um hospital publico do estado de Sergipe. Rev Fac Odontol Porto Alegre 2010; 51(1):11-4.

23. Montovani JC, Campos LMP, Gomes MA, Moraes VRS, Ferreira FD, Nogueira EA. Etiologia e incidência das fraturas faciais em adultos e crianças: experiência em 513 casos. Rev Bras Otorrinolaringol 2006; 72(2):235-41.

24. Adeodato, VG, Carvalho RR, Siqueira VR, Sousa FGM. Quality of life and depression in women abused by their partners. Rev Saúde Pública 2005; 39(1):108-13.

25. Aranega AM, Panzoni D, Garcia-Junior IR, Clicie SV, Magro-Filho O. Etiologia e incidência de traumas faciais relacionados a violência doméstica à mulher. Rev Saude Pública. $2010 ; 5(5): 118-24$.

26. Vieira CL, Araujo DCC, Ribeiro MLS, Laureano Filho JR. Lesão de tecido mole em pacientes vítimas de trauma buco-maxilo-facial. Rev Cir Traumatol Buco-Maxilo-fac 2013; 13(1):89-96. 


\section{Anexos}

Quadro 1 - Resumo dos estudos analisados sobre traumas faciais, 2010-2015

\begin{tabular}{|c|c|c|c|}
\hline Estudo & Objetivo & Método & Resultados \\
\hline $\begin{array}{l}\text { Souza et al. }{ }^{7} \\
(2010)\end{array}$ & $\begin{array}{l}\text { Realizar um estudo epide- } \\
\text { miológico das fraturas de } \\
\text { face em crianças em um } \\
\text { serviço de urgência. }\end{array}$ & $\begin{array}{l}\text { Estudo de corte transversal de } 42 \text { pa- } \\
\text { cientes com idades variando entre } 0 \text { à } \\
17 \text { anos, portadores de fraturas de face, } \\
\text { tratados no Setor de Cirurgia Buco- } \\
\text {-Maxilo-Facial, de jan de } 2000 \text { a dez de } \\
2003 \text {. }\end{array}$ & $\begin{array}{l}\text { Sexo masc }(81 \%) \text {, fratura de mandíbula }(70 \%) \text {, } \\
\text { principais causas: acidentes de trânsito e queda. } \\
\text { O verão foi a época de maior acometimento e } \\
\text { mais de } 80 \% \text { dos casos necessita de cirurgia. }\end{array}$ \\
\hline $\begin{array}{l}\text { Martins et } \\
\text { al. }{ }^{9}(2013)\end{array}$ & $\begin{array}{l}\text { Avaliar se a Lei Seca cum- } \\
\text { priu sua meta após três } \\
\text { anos da promulgação. }\end{array}$ & $\begin{array}{l}\text { Estudo de corte transversal. Avaliou } 265 \\
\text { pacientes com fraturas craniofaciais } \\
\text { submetidos a tratamento cirúrgico em } \\
\text { um hospital universitário, em dois perío- } \\
\text { dos: antes (2005 a 2008) e após a im- } \\
\text { plantação da lei (2008 a 2011). }\end{array}$ & $\begin{array}{l}149 \text { pacientes (56\%) antes e } 116(44 \%) \text { após a } \\
\text { lei. Predomínio da faixa etária entre } 19 \text { e } 40 \text { anos. } \\
\text { Principais causas: acidentes automobilísticos, } \\
\text { agressões físicas e quedas. O abuso de álcool foi } \\
\text { identificado em } 15,4 \% \text { dos pacientes antes e } 19 \% \\
\text { após. A mandíbula e o complexo maxilozigomá- } \\
\text { tico foram mais acometidos. }\end{array}$ \\
\hline $\begin{array}{l}\text { Stolz et al. }{ }^{15} \\
(2011)\end{array}$ & $\begin{array}{l}\text { Traçar o perfil epidemio- } \\
\text { lógico quanto ao sexo, } \\
\text { idade, localização da } \\
\text { fratura, fator etiológico e } \\
\text { tratamento dos pacientes } \\
\text { atendidos no HUSM. }\end{array}$ & $\begin{array}{l}\text { Estudo de corte transversal do período } \\
\text { de janeiro de } 2005 \text { à dezembro de } 2007 \\
\text { em que foram avaliados } 479 \text { prontu- } \\
\text { ários, dos quais } 166 \text { eram referentes à } \\
\text { fratura e se enquadravam nos quesitos } \\
\text { de inclusão do estudo. }\end{array}$ & $\begin{array}{l}\text { Sexo masc: }(83,3 \%) \text {. Faixa etária mais acometida } \\
\text { foi de } 21 \text { a } 25 \text { anos }(15,66 \%) \text {. Média de idade } \\
\text { para o sexo fem foi } 40 \text { anos e para o sexo masc } 31 \\
\text { anos. Agressão física }(24,70 \%) \text {, acidente de mo- } \\
\text { tocicleta }(12,05 \%) \text {, de carro }(8,43 \%) \text { e atropela- } \\
\text { mento }(5,42 \%) \text {. Os ossos: nasais }(31,33 \%) \text {, com- } \\
\text { plexo zigomático }(30,72 \%) \text {, mandíbula }(28,31 \%) \\
\text { e maxila }(4,22 \%) \text {. }\end{array}$ \\
\hline $\begin{array}{l}\text { Silva et al. }{ }^{17} \\
(2011 \mathrm{a})\end{array}$ & $\begin{array}{l}\text { Avaliar o perfil epidemio- } \\
\text { lógico de } 70 \text { pacientes } \\
\text { com fratura de mandíbula } \\
\text { e foram operados no pe- } \\
\text { ríodo de janeiro de } 2005 \\
\text { a dezembro de } 2009 .\end{array}$ & $\begin{array}{l}\text { Estudo de corte transversal. Avaliou- } \\
\text {-se sexo, idade, cor, procedência, sítio } \\
\text { anatômico da fratura, etiologia, fraturas } \\
\text { associadas, tratamento, tempo de inter- } \\
\text { nação e complicações. }\end{array}$ & $\begin{array}{l}\text { Sexo masc: }(90 \%) \text {, com média de idade de } 28,25 \text {. } \\
80 \% \text { dos pacientes era de cor branca e proceden- } \\
\text { te do interior }(68 \%) \text {. Parassínfise: região mais aco- } \\
\text { metida. Acidentes de trânsito }(70 \%) \text {. Os acidentes } \\
\text { motociclísticos }(55,7 \%) \text { foram mais prevalentes. }\end{array}$ \\
\hline $\begin{array}{l}\text { Marques } \\
\text { et al. }{ }^{12}(2010)\end{array}$ & $\begin{array}{l}\text { Analisar a frequência e } \\
\text { etiologia das fraturas de } \\
\text { face, em } \mathrm{BH}-\mathrm{MG} \text { entre } \\
\text { janeiro de } 2007 \text { e dezem- } \\
\text { bro de } 2009 \text {. }\end{array}$ & $\begin{array}{l}\text { Estudo descritivo de corte transversal. } \\
\text { Análise de } 740 \text { pacientes com uma ou } \\
\text { mais fraturas, totalizando } 923 \text { fraturas } \\
\text { de face. }\end{array}$ & $\begin{array}{l}\text { Fratura de nariz }(37 \%) \text { seguido de mandíbula } \\
(29 \%) \text {. Sexo masc }(79 \%) \text {. Média de idade: } 31 \\
\text { anos. Agressão física }(27 \%) \text { seguido por queda } \\
(23 \%) \text {. }\end{array}$ \\
\hline $\begin{array}{l}\text { Cavalcanti } \\
\text { et al. }{ }^{13} \\
(2012 \mathrm{a})\end{array}$ & $\begin{array}{l}\text { Analisar a ocorrência de } \\
\text { lesões orofaciais em prati- } \\
\text { cantes de esportes de luta. }\end{array}$ & $\begin{array}{l}\text { Estudo de corte transversal. Aplicação } \\
\text { de um questionário a } 85 \text { praticantes de } \\
\text { esportes de luta em academias de Cam- } \\
\text { pina Grande-PB. Variáveis: sexo, idade, } \\
\text { número e tipo de esporte praticado, im- } \\
\text { portância e uso do protetor bucal, tipo } \\
\text { de protetor, ocorrência de lesão associa- } \\
\text { da à prática esportiva, região acometida } \\
\text { e injúria na cavidade bucal. }\end{array}$ & $\begin{array}{l}\text { Sexo masculino: }(76,5 \%) \text {. Média de idade de } 27,4 \\
\text { anos. } 90,6 \% \text { fazia um único esporte de luta. Pre- } \\
\text { domínio: boxe }(46,2 \%) \text {, Jiu-Jitsu }(25,8 \%) \text {. } 95,3 \% \\
\text { afirmou conhecer a importância dos protetores } \\
\text { bucais. } 41,7 \% \text { utilizavam durante a prática es- } \\
\text { portiva. } 51,4 \% \text { utilizavam o protetor termoplásti- } \\
\text { co. } 43,5 \% \text { sofreram injúrias. Lesões bucais foram } \\
\text { reportadas por } 16,5 \% \text { dos praticantes, todos do } \\
\text { sexo masc. }\end{array}$ \\
\hline $\begin{array}{l}\text { Aragão } \\
\text { et al. }{ }^{20}(2010)\end{array}$ & $\begin{array}{l}\text { Verificar o perfil epide- } \\
\text { miológico das fraturas da } \\
\text { face em SE no período de } \\
2004 \text { a } 2006 \text {. }\end{array}$ & $\begin{array}{l}\text { Estudo de corte transversal, sendo rea- } \\
\text { lizado por meio de análise de prontuá- } \\
\text { rios de } 263 \text { pacientes atendidos no setor } \\
\text { de trauma de um hospital público com } \\
\text { diagnóstico de fratura dos ossos da face. }\end{array}$ & $\begin{array}{l}\text { Sexo masc. }(85,17 \%) \text {. Faixa etária mais acometida } \\
\text { foi a } 3^{\text {a }} \text { década de vida. As causas mais comuns: } \\
\text { acidentes motociclísticos }(22,81 \%) \text {, violência in- } \\
\text { terpessoal }(14,44 \%) \text {, acidentes automobilísticos } \\
(8,36 \%) \text {. Fraturas de mandíbula }(39 \%) \text { seguido do } \\
\text { osso zigomático }(22 \%) \text {. }\end{array}$ \\
\hline $\begin{array}{l}\text { Carvalho } \\
\text { et al. }{ }^{10} \\
(2010)\end{array}$ & $\begin{array}{l}\text { Avaliar dados epidemio- } \\
\text { lógicos de atendimento } \\
\text { em trauma facial. }\end{array}$ & $\begin{array}{l}\text { Estudo de corte transversal em que foram } \\
\text { revisados } 335 \text { prontuários de pacientes } \\
\text { com trauma facial tratados pelo Serviço } \\
\text { de Otorrinolaringologia, no período de } \\
\text { janeiro de } 2002 \text { a dezembro de } 2008 \text {. Va- } \\
\text { riáveis: idade, sexo, etiologia, local anatô- } \\
\text { mico da fratura, lesão associada, consumo } \\
\text { de álcool, tratamento e hospitalização. }\end{array}$ & $\begin{array}{l}\text { A maioria dos pacientes são homens adultos jo- } \\
\text { vens com uma proporção masculino:feminino } \\
\text { de } 4: 1 . \text { Violência interpessoal é a causa mais } \\
\text { prevalente }(27,9 \%) \text { e acidente automobilístico } \\
(16,6 \%) \text {. Mandíbula é a mais fraturada }(44,2 \%) \\
\text { e nasal (18,9\%). Houve consumo de álcool } \\
\text { em } 41,1 \% \text { dos pacientes com uma proporção } \\
\text { masculino:feminino de } 11,2: 1 \text {. }\end{array}$ \\
\hline $\begin{array}{l}\text { Silva et al. }{ }^{18} \\
(2011 b)\end{array}$ & $\begin{array}{l}\text { Traçar um perfil dos pa- } \\
\text { cientes que sofreram esse } \\
\text { tipo de trauma. }\end{array}$ & $\begin{array}{l}\text { Estudo de corte transversal. Foram ana- } \\
\text { lisados } 194 \text { casos de trauma facial aten- } \\
\text { didos em Fortaleza (Ceará), entre } 2005 \\
\text { e } 2009 .\end{array}$ & $\begin{array}{l}\text { Média de idade: } 30 \text { anos. Sexo masc. } 80,4 \% \text {, e } \\
\text { proporção homem/mulher } 4,1: 1 \text {. Idosos e crian- } \\
\text { ças corresponderam a } 5,7 \% \text {. Acidentes de transi- } \\
\text { to }(60,31 \%) \text {, acidentes com motociclistas repre- } \\
\text { sentam } 44,8 \% \text { do total. Violência interpessoal } \\
18,6 \% \text {. Era do interior }(57,2 \%) \text {, porém os da ca- } \\
\text { pital tiveram maior proporção de fraturas relacio- } \\
\text { nadas à violência interpessoal }(66,66 \%) \text {. O osso } \\
\text { mais fraturado foi a mandíbula }(30,49 \%) \text {, seguida } \\
\text { pelo osso nasal }(22,2 \%) \text {. }\end{array}$ \\
\hline
\end{tabular}




\begin{tabular}{|c|c|c|c|}
\hline $\begin{array}{l}\text { Borguese et } \\
\text { al. }{ }^{16}(2011)\end{array}$ & $\begin{array}{l}\text { Analisar os prontuários } \\
\text { de } 144 \text { pacientes e saber } \\
\text { quais as principais causas } \\
\text { desse tipo de fratura no } \\
\text { período de } 2002 \text { a outu- } \\
\text { bro de } 2008 .\end{array}$ & $\begin{array}{l}\text { O estudo de corte transversal. As infor- } \\
\text { mações foram obtidas a partir da revisão } \\
\text { de prontuários médicos, enfocando va- } \\
\text { riáveis demográficas, relativas a atendi- } \\
\text { mento, procedimento cirúrgico e segui- } \\
\text { mento pós-operatório dos pacientes. }\end{array}$ & $\begin{array}{l}\text { O paciente tipicamente afetado pelas fraturas na- } \\
\text { sais é o indivíduo adulto jovem e do sexo mascu- } \\
\text { lino. O tratamento cirúrgico por meio de redução } \\
\text { fechada promove resultados aceitáveis, se respei- } \\
\text { tados os princípios de avaliação correta da lesão } \\
\text { e do momento de indicação do tratamento. }\end{array}$ \\
\hline $\begin{array}{l}\text { Cavalcanti et } \\
\text { al. }{ }^{14}(2012 b)\end{array}$ & $\begin{array}{l}\text { Avaliar os traumatismos } \\
\text { maxilofaciais em crianças } \\
\text { e adolescentes. }\end{array}$ & $\begin{array}{l}\text { Estudo descritivo de corte transversal. } \\
\text { Analisou } 941 \text { pacientes de } 1 \text { a } 18 \text { anos } \\
\text { portadores de trauma facial atendidos } \\
\text { no período de junho de } 2007 \text { a junho } \\
\text { de } 2009 \text { em dois centros de trauma do } \\
\text { município. }\end{array}$ & $\begin{array}{l}\text { Razão entre os sexos - } 2: 1 \text {. Faixa etária de maior } \\
\text { acometimento: de } 1 \text { a } 4 \text { anos }(28,5 \%) \text {. As que- } \\
\text { das }(40,6 \%) \text { e os acidentes de transporte terrestre } \\
(20,1 \%) \text { foram os agentes etiológicos mais pre- } \\
\text { valentes. Predomínio dos ossos nasais }(31,5 \%) \text { e } \\
\text { o zigomático }(22,8 \%) \text {. Traumatismo dentário foi } \\
\text { identificado em } 10,2 \% \text { das vítimas. }\end{array}$ \\
\hline $\begin{array}{l}\text { Martins } \\
\text { Junior et } \\
\text { al., }{ }^{11}(2010)\end{array}$ & $\begin{array}{l}\text { Levantar o perfil epide- } \\
\text { miológico de } 222 \text { pacien- } \\
\text { tes de fraturas faciais en- } \\
\text { tre } 2004 \text { e } 2009 .\end{array}$ & $\begin{array}{l}\text { Estudo descritivo de corte transversal. } \\
\text { Foram consideradas as variáveis sexo, } \\
\text { idade, profissão, grau de escolaridade, } \\
\text { procedência, local e número de ossos } \\
\text { envolvidos, etiologia e tempo médio de } \\
\text { internação dos pacientes. }\end{array}$ & $\begin{array}{l}\text { Sexo masculino: } 178 \text { ( } 80,1 \%) \text {. Média de idade: } \\
29,6 \text { anos. Residia na cidade de Blumenau, } 175 \\
(78,82 \%) \text {. A agressão física foi a principal res- } \\
\text { ponsável pela indicação cirúrgica com } 79 \text { casos } \\
(35,58 \%) \text {, com envolvimento de um osso em } 193 \\
\text { casos }(86,9 \%) \text {. Principal osso acometido: mandí- } \\
\text { bula, } 90 \text { casos }(40,54 \%) \text {. }\end{array}$ \\
\hline $\begin{array}{l}\text { Santos et al. }{ }^{20} \\
(2012)\end{array}$ & $\begin{array}{l}\text { Analisar os traumatismos } \\
\text { BMF e investigar a etio- } \\
\text { logia } \\
\text { e os fatores associados } \\
\text { no Serviço de CTBMF de } \\
\text { Feira de Santana, Bahia, } \\
\text { no período de novembro } \\
\text { de } 2008 \text { a novembro de } \\
2009 \text {. }\end{array}$ & $\begin{array}{l}\text { Estudo descritivo de corte transversal. O } \\
\text { material ( } 657 \text { prontuários) foi submetido } \\
\text { à análise quantitativa dos traumatismos } \\
\text { BMF, bem como sua etiologia, fatores } \\
\text { associados, regiões anatômicas mais } \\
\text { acometidas e características sociode- } \\
\text { mográficas, buscando traçar correlações } \\
\text { com o momento do trauma. }\end{array}$ & $\begin{array}{l}\text { Dentre as doze categorias referentes à etiologia, a } \\
\text { violência interpessoal foi a causa mais prevalente } \\
(25,4 \%) \text {. O sexo masculino: } 76,3 \% \text {. Faixa etária } \\
\text { de maior risco foi menor ou igual à idade de } 30 \\
\text { anos } \\
\text { (63,8\%). A mandíbula mostrou-se o osso mais } \\
\text { atingido. }\end{array}$ \\
\hline $\begin{array}{l}\text { Santana et } \\
\text { al. }{ }^{19}(2011)\end{array}$ & $\begin{array}{l}\text { Caracterizar as lesões cor- } \\
\text { porais e faciais em mulhe- } \\
\text { res que se submeteram a } \\
\text { pericia no IML do muni- } \\
\text { cípio de Recife, PE, Brasil, } \\
\text { no ocorridas nos meses } \\
\text { de janeiro, abril e dezem- } \\
\text { bro de } 2005 \text { e } 2006 \text { e ja- } \\
\text { neiro e abril de } 2007 \text {. }\end{array}$ & $\begin{array}{l}\text { Estudo quantitativo e analítico de corte } \\
\text { transversal. Foram estudadas as lesões } \\
\text { corporais e faciais em mulheres subme- } \\
\text { tidas a exame de corpo de delito no IML } \\
\text { de Recife, PE. }\end{array}$ & $\begin{array}{l}\text { Predominaram na amostra as lesões do tipo con- } \\
\text { tundente e em mais de uma região corporal. Na } \\
\text { face, a região mais acometida pela violência foi o } \\
\text { terço médio. As lesões mais frequentes associadas } \\
\text { aos tecidos foram as de tecidos moles. O agres- } \\
\text { sor foi predominantemente o conjuge e as lesões } \\
\text { classificadas como leve foram as mais comuns. }\end{array}$ \\
\hline $\begin{array}{l}\text { Silva et al. }{ }^{18} \\
\text { (2011c) }\end{array}$ & $\begin{array}{l}\text { Analisar o perfil epide- } \\
\text { miológico dos traumas } \\
\text { dentofaciais nos pacien- } \\
\text { tes - } 2009 \text { - Curitiba (PR). }\end{array}$ & $\begin{array}{l}\text { Estudo descritivo de corte transversal. } \\
\text { Foram analisados, retrospectivamente, } \\
\text { os } 1380 \text { prontuários em busca das se- } \\
\text { guintes variáveis: data e dia da semana } \\
\text { em que ocorreu o trauma, idade, sexo } \\
\text { do paciente, a etiologia do trauma, os } \\
\text { dentes acometidos, tipo de trauma den- } \\
\text { tário, traumas associados, presença ou } \\
\text { não de lesões em partes moles, se houve } \\
\text { ou não óbito e se foi necessária sutura. }\end{array}$ & $\begin{array}{l}\text { Sexo masculino: } 66,37 \% \text {. Faixa etária dos } 0 \text { aos } \\
\text { dez anos: } 30,47 \% \text {. Quedas: }(53,92 \%) \text {. Domingos } \\
(17,39 \%) \text {, período noturno }(35,90 \%) \text {, lesão coro- } \\
\text { nária }(30,25 \%) \text {, dentes mais acometidos foram os } \\
\text { IC }(45,64 \%) \text {. }\end{array}$ \\
\hline $\begin{array}{l}\text { Santos et al. } .^{21} \\
(2013)\end{array}$ & $\begin{array}{l}\text { Descrever o perfil epide- } \\
\text { miológico dos casos de } \\
\text { traumas faciais ocorridos } \\
\text { em Salvador (BA). }\end{array}$ & $\begin{array}{l}\text { Estudo descritivo de corte transversal. } \\
\text { Levantamento de dados secundários do } \\
\text { DPT da SSP do Estado da Bahia - } 2008 .\end{array}$ & $\begin{array}{l}\text { Mediade idade: } 33 \text { anos. Sexo feminino: } 52 \% \text {. } \\
\text { Sexo masculino: } 48 \% \text {. Na sua maioria, as vítimas } \\
\text { eram de etnia parda. O trauma mais prevalente } \\
\text { foi laceração de tecido mole, seguida de outras } \\
\text { lesões, sendo a agressão física o principal meca- } \\
\text { nismo do trauma. }\end{array}$ \\
\hline
\end{tabular}

\section{Endereço para correspondência:}

Endereço para correspondência:

Tatiana Frederico de Almeida

Rua João Bião de Cerqueira 251, Pituba

41.830.580 Salvador-BA

Fone: (71) 3351-4447/9933-4886

E-mail: tatifrederico@yahoo.com.br

Recebido: 07/07/2016. Aceito: 26/03/2017. 